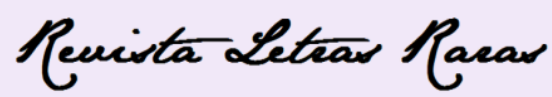

ISSN: 2317-2347 - Vol. 5, Ano 5, № 1 - 2016

\title{
Pelos caminhos da extensão universitária na UFCG: formação docente para o ensino de Libras
}

\author{
Prof $^{a}$ Dr $^{\mathrm{a}}$ Eleny Gianini \\ Prof $^{a}$. Dra ${ }^{\mathrm{a}}$. Niédja Maria Ferreira de Lima \\ Prof $^{\mathrm{a}} \mathrm{Dr}^{\mathrm{a}}$ Shirley Barbosa das Neves Porto
}

\begin{abstract}
Resumo: Este artigo se constitui como um relato de nossa experiência pelos caminhos da extensão universitária, que realizamos na Universidade Federal de Campina Grande (UFCG), desde os anos de 1983. Ao apresentarmos nossas ações na formação continuada de docentes de LIBRAS, discorremos sobre as concepções de educação de surdos (SAKCS, 1998; SKLIAR, 1999; MOURA, 2000, entre outros) e as visões sobre ensino de língua vigentes ao longo desse processo, no espaço de Escolas para surdos e no contexto geral da linguística, em cada período (TRAVAGLIA, 1996; LACERDA E OUTROS, 2000; SLOMSKY, 2010; FUZA E OUTROS, 2011), embasadas em princípios norteadores do processo de formação docente (FACCI, 2004; GUIMARÃES, 2004; VÁSQUESZ, 2007; GIANINI, 2012). Concomitantemente, apresentamos nossas impressões e algumas considerações sobre esse processo, para nós importante, pois se contribuímos para a profissionalização dos docentes surdos de LIBRAS, certamente eles contribuíram para a nossa. Por fim, concluímos acreditando que a formação coletiva e continuada fortalece o enfrentamento das adversidades na busca da conquista por escolas bilíngues públicas de qualidade que venham a atender os anseios da comunidade surda.
\end{abstract}

Palavras chave: Extensão universitária. Formação continuada. Ensino de LIBRAS. Docentes surdos.

\section{THE WAYS OF UNIVERSITY EXTENSION IN THE UFCG: TEACHER TRAINING FOR THE LIBRAS TEACHING}

\begin{abstract}
This article is an account of our experience in the paths of University extension, which we performed at the Federal University of Campina Grande (UFCG), since the years of 1983. To perform our actions in continuous formation of teachers of LIBRAS, we announce about the conceptions of education of the deaf (SAKCS, 1998; SKLIAR, 1999; MOURA, 2000) and the teaching language conceptions in force throughout this process, in Schools for the deaf and in the general context of Linguistics, in each period (TRAVAGLIA, 1996; LACERDA and others, 2000; SLOMSKY, 2010; FUZA and others, 2011), based on the guiding principles of the process of teacher training (FACCI, 2004; GUIMARÃES, 2004; VÁSQUESZ, 2007; GIANINI, 2012). At the same time, we present our impressions and some considerations on this process, important for us, because if we contribute to the professionalization of teachers deaf pounds, they certainly contributed to our. Finally, we believe that the collective and continued training strengthens the facing adversity in search of conquest for bilingual public schools of quality that will meet the concerns of the deaf community.
\end{abstract}

\section{0 caminho do ensino de LIBRAS: processos de formação docente}

Nossa caminhada pela extensão universitária na área da Educação de Surdos e do Ensino de LIBRAS teve início no ano de 1983 com a fundação, por parte da universidade, de uma escola para surdos em Campina Grande/PB. A criação da referida escola teve por objetivo proporcionar campo de estágio para as estudantes que cursavam a Habilitação de 


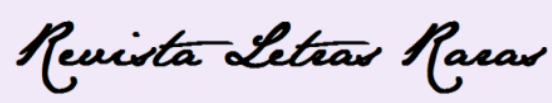

ISSN: 2317-2347 - Vol. 5, Ano 5, № 1 - 2016

Educação de Deficientes da Audiocomunicação, do Curso de Licenciatura em Pedagogia, da Universidade Federal de Campina Grande ${ }^{1}$.

Do ano de 1983 até 1996 a escola não contava com docentes surdos para ensino de LIBRAS. Isso se dava em função das concepções Oralista e da Comunicação Total que fundamentavam a proposta pedagógica da Escola. A partir de 1995, a Escola assume a perspectiva bilíngue para a educação de surdos e a presença de docentes surdos para o ensino da LIBRAS passa a ser fundamental sob duas perspectivas. De acordo com Gianini (2012), a primeira "diz respeito a que servissem de referência linguística para a aquisição natural da LIBRAS, por meio das interações e trocas de experiências que mantinham com as crianças" (p. 138). A segunda

concerne ao desenvolvimento de uma identidade positiva de pessoa surda. $\mathrm{O}$ fato de pessoas surdas exercerem, naquela ocasião, a função de docentes na escola, e não mais funções de desprestígio social, contribuía de modo significativo para um processo de empoderamento de pessoa surda junto à comunidade de ouvintes e de surdos. (GIANINI, 2012, p. 136 e 137).

Como se pode observar, a presença e importância dos docentes surdos se dá muito mais em função do papel deles no desenvolvimento linguístico e identitário, do que propriamente dito às responsabilidades inerentes a um professor de língua.

Vemos esse movimento como consequência da nossa formação e atuação acadêmica na área de educação, que focava o processo de ensino da LIBRAS na questão pedagógica e não dos conhecimentos linguísticos relativos a essa língua e ao seu ensino.

Com as condições objetivas que existentes no momento, tanto em relação aos conhecimentos teóricos e práticos sobre quanto implementar propostas de educação bilíngue para surdos, como a inexistência de docentes de LIBRAS com formação específica, a formação oferecida aos docentes da Escola, tinha uma perspectiva centrada no fazer pedagógico em geral, não havendo ações mais pontuais relativas ao ensino de LIBRAS propriamente dito. Assim, tanto os docentes ouvintes, responsáveis pelos diversos componentes curriculares, quanto os docentes surdos, responsáveis pelo ensino de LIBRAS, participavam de estudos teórico-metodológicos em conjunto.

A partir de 2002, acompanhamos o reconhecimento da LIBRAS como língua das comunidades surdas do Brasil (Lei 10.436/02), a expansão de pesquisas linguísticas sobre

\footnotetext{
${ }^{1}$ Naquela época ainda éramos vinculados à Universidade Federal da Paraíba. A partir de 2002 houve um desmembramento e a criação da Universidade Federal de Campina Grande
} 


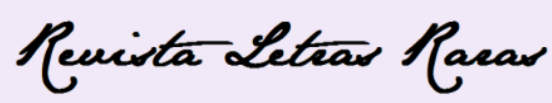

ISSN: 2317-2347 - Vol. 5, Ano 5, № 1 - 2016

essa língua e seu ensino, e o surgimento de propostas de curso de formação docente na área das letras e não mais apenas no âmbito da pedagogia.

Da mesma forma aqui em Campina Grande, passamos, a partir de 2002, a oferecer uma formação específica para os docentes surdos. Em um primeiro momento, voltada aos aspectos didáticos do ensino da LIBRAS e de seu currículo escolar. Em um segundo momento, a partir de 2012, buscando contemplar saberes linguísticos da LIBRAS e suas implicações para o ensino.

Apresentar o desenrolar e algumas considerações sobre esse processo é o objetivo deste artigo.

\section{0 início do ensino de LIBRAS em Campina Grande}

No início dos anos 1990, o modelo de educação Oralista para surdos encontrava-se falido, quer localmente como mundialmente. Os resultados esperados para o desenvolvimento dos surdos não foram alcançados, apesar de mais de cem anos de investimentos terapêuticos, tecnológicos e educacionais. $\mathrm{O}$ fracasso educacional gerado por esse modelo nos incomodava.

Nesse mesmo tempo, descortinava-se no Brasil a Comunicação Total (CT) para a educação de surdos, que segundo Moura (2000) foi definida como "uma filosofia que incorpora as formas de comunicação auditivas, manuais e orais apropriadas para assegurar uma comunicação efetiva com as pessoas surdas" (p, 57).

Esta nova abordagem abriu espaço para que a LIBRAS saísse da clandestinidade, sendo dado aos surdos o direito até então negado, de usarem sinais para aprenderem, se expressarem e se comunicarem livre e publicamente, como faziam entre pares no seio de uma comunidade surda em processo de legitimação. Convém, no entanto, lembrar que a utilização de sinais na metodologia da Comunicação Total não significava ainda o emprego da língua de sinais no processo educativo. O uso dos sinais na $\mathrm{CT}$ representava apenas um suporte para o falado oralmente, e tinha como objetivo oferecer uma imagem visual da fala para os alunos, ao mesmo tempo em que ouviam e faziam leitura orofacial.

Como podemos observar, a LIBRAS foi tratada como um dispositivo didático com fins ao desenvolvimento da linguagem oral. Entretanto, apesar das limitações que a CT impunha à LIBRAS ao não considera-la como a língua constituinte da pessoa surda e, portanto, fundamental como língua para as interações sociais e para instrução educacional, 


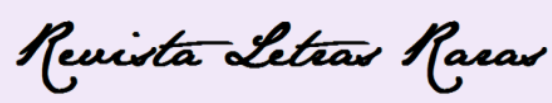

ISSN: 2317-2347 - Vol. 5, Ano 5, № 1 - 2016

inegavelmente contribuiu para que a Escola se tornasse um espaço democrático de uso da língua de sinais. Além do mais, a adoção do uso da LIBRAS como dispositivo pedagógico pela Escola levou a que surdos fossem convidados a ministrar aulas de LIBRAS para os docentes, ensinando sinais que pudessem apoiar e facilitar a comunicação professor - aluno. Não havia uma preocupação com a formação de professores de LIBRAS, muito menos com estudos linguísticos sobre essa língua.

A necessidade de formação de professores de LIBRAS surge, quando à procura de novas possibilidades educacionais que favorecessem o desenvolvimento das pessoas surdas, adotamos o Bilinguismo para a educação dos surdos na Escola.

O Bilinguismo na educação de surdos baseia-se numa concepção sociocultural da surdez, que compreende o surdo a partir de sua excelência visual, e, portanto, como participante de um grupo que se constitui linguisticamente por meio de uma língua visualgestual. (SACKS, 1998; SKLIAR, 1999; MOURA, 2000; SLOMSKI, 2010)

A adoção desse modelo de educação para surdos nos impôs, de imediato, três necessidades. Uma, tornarmo-nos usuários competentes de LIBRAS; a outra, estudá-la linguisticamente e, finalmente, aprender a ensiná-la. Para aprendê-la, estudar e ensinar necessitávamos de docentes de LIBRAS, tornando fundamental a presença desses na Escola.

A inexistência de profissionais surdos que pudessem exercer a função de professores de LIBRAS, levou-nos a alçar à função de docentes alguns surdos que já pertenciam ao quadro de funcionários do Município e do Estado, exercendo atividades de serviços gerais, auxiliar de biblioteca e digitador. Esses primeiros docentes da escola de surdos de Campina Grande apresentavam-se do seguinte modo: (1) surdos usuários da LIBRAS, pertencentes à primeira geração da comunidade surda local; (2) ex-alunos da Escola; (3) nível de escolaridade que se limitava aos anos iniciais do Ensino Fundamental (GIANINI, 2012).

Soma-se ao perfil dos docentes surdos, o fato de que, naquele momento, havia pouca compreensão do ponto de vista teórico-metodológico, das reais implicações de uma proposta bilíngue em uma escola para surdos, o que os levou a assumir, da forma que lhes foi possível, duas grandes tarefas: auxiliar os professores ouvintes na Educação Infantil e Ensino Fundamental, em atividades como contar histórias, explorar conteúdos escolares, a partir do planejamento didático dos professores ouvintes; e ensinar LIBRAS para a comunidade ouvinte da Escola. 


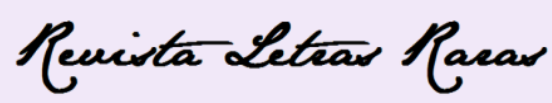

ISSN: 2317-2347 - Vol. 5, Ano 5, № 1 - 2016

Nesse momento não se colocava o ensino de LIBRAS sob a perspectiva de primeira ou segunda língua. Para os alunos surdos, ensinavam sinais de cores, objetos escolares, frutas etc., além de serem responsáveis pela contação de histórias infantis. Aos ouvintes, professores e pais de alunos, ensinavam LIBRAS, sendo as aulas ministradas centradas no ensino de vocabulário, mediante listas de palavras que eram escritas no quadro, sem nenhuma contextualização linguística ou social.

Relatos de suas experiências na docência, nessa época, têm como tônica que "não sabiam nem o que nem como ensinar" (GIANINI, 2012, p.137). Essa falta de conhecimento teórico-metodológico levou-os ao ensino de LIBRAS a partir de suas experiências de estudante de língua portuguesa, baseadas no modelo Oralista, que privilegiava o ensino de palavras isoladas com fins de treinamento de fala.

Para Lacerda e outros (2000), o trabalho com surdos no Oralismo "está voltado para aquisição de linguagem oral, visando à aquisição de um vocabulário básico" (p.24). Respaldado numa concepção estruturalista de língua, "o adulto ouvinte fornece à criança surda material linguístico por meio de lista de palavras ou frases previamente elaboradas, cuja escolha se baseia no critério de facilidade para falar" (idem, p. 25).

A visão estruturalista da linguagem tem a concepção de que:

as pessoas não se expressam bem porque não pensam. A expressão se constrói no interior da mente, sendo sua exteriorização apenas uma tradução. A enunciação em um ato monológico, individual, que não é afetado por outro nem pelas circunstâncias que constituem a situação social em que a enunciação acontece. (TRAVAGLIA, 1996, p. 21)

Sendo esta concepção a base da prática Oralista, o grande objetivo de falar bem para expressar bem os pensamentos, dificilmente foi alcançada pelos surdos, restando para eles uma visão de língua como lista de palavras.

No âmbito da Escola, a pluralidade de situações comunicativas possibilitava que a língua se afirmasse, de fato, como instrumento de interação entre os surdos, provocando o desenvolvimento da própria língua e gerando novas necessidades para o seu ensino.

\section{0 início de uma formação específica para docentes de LIBRAS surdos}

A partir dos anos 2000, o Bilinguismo se sedimentava na educação de surdos e a LIBRAS ocupava cada vez mais espaços acadêmicos e de lutas da comunidade surda para o 


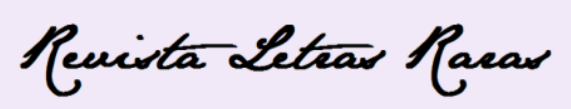

ISSN: 2317-2347 - Vol. 5, Ano 5, № 1 - 2016

seu reconhecimento. O reconhecimento da LIBRAS como língua da comunidade surda nacional, por meio da Lei 10.436, de 2002 (BRASIL, 2002), foi o marco desse processo.

No âmbito da Escola, nesse mesmo período, a LIBRAS foi inserida como um dos componentes curriculares, tirando os docentes surdos da condição de auxiliar de sala dos professores ouvintes e levando-os à condição de professores de LIBRAS como primeira língua (L1) para os alunos surdos. Se antes todo o planejamento didático pedagógico era feito pelos professores ouvintes dos demais componentes curriculares, sendo os docentes surdos apenas coadjuvantes no processo de ensino-aprendizagem, agora, eles seriam protagonistas de suas práticas em sala de aula. Assim, uma nova necessidade para a formação desses docentes surge: embasá-los de conhecimentos didáticos (plano de aula, metodologias de ensino, avaliação, entre outros).

Gostaríamos de abrir um parêntese neste momento. $\mathrm{O}$ fato de os docentes surdos permanecerem por vários anos como ajudantes dos professores ouvintes, contribuiu de forma significativa para a sua formação docente. Segundo relatos em Gianini (2012), foi observando a prática dos docentes ouvintes, suas formas de planejar e organizar, de preparar materiais didáticos, da relação estabelecida em sala de aula com os alunos, que eles também foram se formando docentes.

Esse conhecimento da prática pedagógica necessitava da apropriação de noções teóricas e metodológicas da LIBRAS para que a práxis educacional pudesse acontecer (FACCI, 2004; VÁSQUEZ, 2007). A formação desses docentes passa a ser voltada para sua autonomia pedagógica, mas ainda muito centrada nos conhecimentos da área da educação e não tanto para os saberes da área da linguística.

A partir desse momento, os encaminhamentos sobre o ensino de LIBRAS começaram a ser feitos de forma separada e independente dos planejamentos dos professores ouvintes. Além das necessidades distintas dos grupos de docentes - os professores surdos planejando aulas de LIBRAS como L1 e os ouvintes, os demais conteúdos -, um agravante impulsionou essa separação: o fato de apesar de há alguns anos todos assumirem a educação bilíngue e defender a LIBRAS como língua das interações na Escola, o espaço da LIBRAS restringia-se a atividades de sala de aula, mas os planejamentos, encontros pedagógicos, reuniões em geral, continuavam sendo realizados por meio da língua portuguesa oral e interpretados para a LIBRAS. Esse privilégio da Língua Portuguesa demostrava que as interações profissionais e 


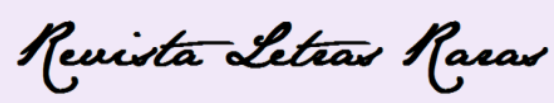

ISSN: 2317-2347 - Vol. 5, Ano 5, № 1 - 2016

pessoais necessárias para que a participação dos docentes surdos fosse efetiva e suas falas realmente consideradas não aconteciam de forma equitativa.

Os encontros para planejamento das aulas de ensino de LIBRAS eram realizados em LIBRAS sem intermediação de intérpretes, proporcionando que pudessem acontecer trocas de saberes mais diretas, permitindo, de forma positiva, na opinião dos docentes surdos, "momentos de estudo, de planejamento, de troca de opiniões e experiências, de adequação do ensino às necessidades dos alunos, de avaliação da execução do planejamento, de construção de um currículo, dentre outros" (GIANINI, 2012, p. 182).

A apropriação destes conhecimentos, que abarcam os saberes teóricos e práticos que o professor precisa dispor para desenvolver os processos de ensino e aprendizagem, são os mobilizados no dia a dia escolar e que identificam a profissionalidade do professor (GUIMARÃES, 2004), possibilitando que o processo de identidade profissional abrangido por duas facetas - a "identidade para si" e a "identidade para o outro" - pudesse ocorrer, se não no âmbito da Escola, pelo menos dentro do grupo dos docentes surdos.

Cabe ressaltar que a este grupo agregou-se, em 2001, a docente de LIBRAS de escola de uma escola para surdos recém-criada no Município de Gado Bravo/PB e em 2005, a docente de outra escola para surdos criada no Município de Aroeiras/PB. Sentíamos que nossa responsabilidade, nesse momento, se ampliava devido à expansão das escolas bilíngues para surdos e do ensino da LIBRAS como L1 para os mesmos.

Em âmbito nacional uma série de ações de afirmação da LIBRAS como língua começaram a acontecer. Desde 1998, a Federação Nacional para Integração e Educação dos Surdos (FENEIS) oferecia cursos para capacitação de Instrutores de LIBRAS $^{2}$, baseados na metodologia LIBRAS em Contexto (FELIPE, 2001a,b), material desenvolvido para o ensino de LIBRAS que conta com livro para o professor, livro do aluno e DVD.

Este material propunha-se a que os professores aprendessem os aspectos fonológicos, morfológicos e sintáticos da LIBRAS, por meio do estudo de noções básicas de sua gramática; conhecessem o Sistema de Transcrição e os princípios das línguas em contexto; adquirissem técnicas de organização e de execução de planos de aulas a partir das unidades do Livro Professor de LIBRAS em Contexto - Curso Básico; e conhecessem aspectos histórico culturais da comunidade surda (FELIPE, 2001a).

\footnotetext{
${ }^{2}$ No Brasil, é feita uma diferença entre Instrutor de LIBRAS e Professor de LIBRAS. O primeiro diz respeito a surdos que ensinam a língua sem formação ou com formação feita por meio de cursos de capacitação. Os segundos, seriam os que tiveram formação em nível superior.
} 


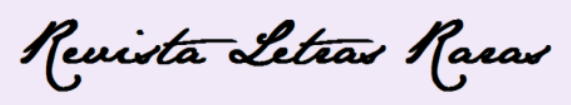

ISSN: 2317-2347 - Vol. 5, Ano 5, № 1 - 2016

Em 2005, o Decreto 5.626 (BRASIL, 2005) que regulamentou a Lei $\mathrm{n}^{\circ}$. 10.432, de 2002 (BRASIL, 2002), instituiu o ensino obrigatório da LIBRAS nos cursos de Fonoaudiologia, Pedagogia e demais licenciaturas (Artigo $3^{\circ}$ ) e estabeleceu, em seu Capítulo III, as orientações necessárias para a formação do professor e do instrutor de LIBRAS.

A Lei e o Decreto, marcos da luta dos surdos para o reconhecimento e uso social da LIBRAS, encabeçada pela FENEIS e apoiada pela comunidade surda, abriram espaço para políticas públicas que visavam atender à formação de docentes de LIBRAS disposta nestes documentos. Entre elas, destacamos os Cursos de Licenciatura e Bacharelado em Letras LIBRAS, criados pela Universidade Federal de Santa Catarina (UFSC), apoiado e financiado pelo Ministério da Educação (MEC) e oferecido na modalidade de Educação à distância de 2006 a 2008, passando a partir de 2009 a ser presencial.

O reconhecimento e expansão da LIBRAS fomentou pesquisas linguísticas e literárias, estudos voltados para seu ensino, proliferando publicações científicas na área, bem como materiais didáticos.

Todo esse cenário levou-nos a, aqui em Campina Grande, mudarmos o enfoque da formação dos docentes de LIBRAS para uma perspectiva de ensino da LIBRAS em contexto, que tem como base a concepção de linguagem como interação social. Uma visão dialógica de ensino de língua, que por meio de diálogos, narrativas e exercícios, propiciem a utilização da língua em contextos variados (FELIPE, 2001b).

De acordo com Fuza, Ohuschi e Menegasse (2011, p. 489), "na verdade, o que ocorre é que as situações ou ideias do meio social são responsáveis por determinar como será produzido o enunciado. Desse modo, a formação da expressão depende das condições sociais, assim, temos o social interferindo no individual".

Antecipando-nos ao disposto no Decreto 5.626/2005 (BRASIL, 2005), quanto à formação de professores, desenvolvemos ao longo dos anos 2004 a 2006, o Curso de Capacitação de Instrutores de LIBRAS, oferecido pela UFCG, com o apoio do PROEXT/2003, 2004, 2005/SESu-MEC. Este Curso teve como objetivo capacitar pessoas surdas com domínio da LIBRAS para atuarem como instrutores desta língua, baseando-se no material LIBRAS em Contexto, acima citado. Deste Curso participaram todos os docentes de LIBRAS das Escolas para surdos integrantes, também, da formação continuada oferecida pela UFCG. Ao mesmo tempo, nesta formação procurou-se mudar a concepção de linguagem e de ensino de língua, antes estruturalista, para uma perspectiva dialógica. 


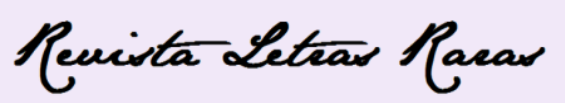

ISSN: 2317-2347 - Vol. 5, Ano 5, № 1 - 2016

Do processo formativo desta época tivemos como resultados: o início da elaboração de um currículo para os anos iniciais do Ensino Fundamental e planejamentos de aulas a partir de temas variados que balizassem o fazer pedagógico, uma vez que, agora, a LIBRAS tornara-se um componente curricular das escolas e os docentes de LIBRAS regentes autônomos dessas aulas. Além do mais, esses docentes, ao compreender a língua como interação social, passaram a ensiná-la de forma dialógica e, portanto, contextualizada.

Ao entrarmos na década atual, a afirmação do ensino de LIBRAS a partir dos gêneros textuais e a produção de materiais para o ensino de língua nesta perspectiva levou-nos a mudar, mais uma vez, o enfoque da formação dos professores de LIBRAS.

\section{Em busca de novos caminhos para o ensino de LIBRAS}

Buscamos nessa trajetória de formação de docentes de LIBRAS, por meio de projetos de extensão, contribuir para a consolidação da educação bilíngue para surdos, entre outras dimensões, no que diz respeito ao conhecimento e à prática pedagógica relativos ao ensino de língua.

Nos últimos anos, com base em uma visão interacionista de ensino de LIBRAS, entendemos que o conhecimento linguístico é elaborado a partir de interações sociais, de modo que "o aluno pode perceber as características da modalidade gestual e visual e seu uso de forma mais clara e presente em seu cotidiano, sabendo discernir as diversas utilizações da língua”. (ALBRES; SARUTA, 2012, p.21).

Neste sentido, é possível afirmar que a língua é constituída e efetivada através da interação verbal, social, em um processo ininterrupto entre interlocutores, visto que ela não é um sistema estável, no qual as formas normativas são idênticas. Os sujeitos não são vistos como agentes isolados dos meios sociais, mas participantes que interagem por meio de diálogos nos quais ocorrem as trocas de experiências e conhecimentos.

Nesta perspectiva, assim como toda língua natural, a LIBRAS se constitui também na interação entre pessoas e atende às necessidades da comunidade surda. Sendo assim, pode-se 


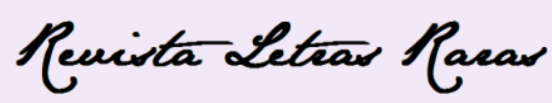

ISSN: 2317-2347 - Vol. 5, Ano 5, № 1 - 2016

afirmar que as línguas de sinais são ilimitadas no sentido de que não há restrição quanto às possibilidades de expressão (SÃO PAULO, 2008).

As interações sociais, por acontecerem fundamentalmente a partir dos gêneros textuais, exigem a sua apropriação pelos membros da comunidade linguística. Assim, para podermos ter interações, apropriamo-nos dos gêneros textuais, que segundo Albres e Saruta (2012, p. 22), "são padrões comunicativos, que, socialmente utilizados, funcionam com uma espécie de formas relativamente estáveis que representam um conhecimento social localizado em situação concreta". Quando falamos em formas relativamente estáveis, entendemos que cada gênero tem características estabilizadas e para colocá-los em uso é preciso dominá-las.

É a partir dos gêneros que se tem a possibilidade da interação sociodiscursiva entre os falantes e também é refletido neles as intenções dos sujeitos. Nessa perspectiva, à medida que os gêneros são produzidos, ficam disponíveis para que as pessoas possam efetivar a interação verbal.

De acordo com Fuza e outros (2011, p. 489):

A expressão realizada pelos interlocutores não é simplesmente realizada pela atividade mental e transmitida pelo indivíduo para o meio social. Entendemos que, na verdade, o que ocorre é que as situações ou ideias do meio social são responsáveis por determinar como será produzido o enunciado. Desse modo, a formação da expressão depende das condições sociais, assim, temos o social interferindo no individual.

A partir dessa afirmação, podemos inferir que os gêneros textuais, sejam eles escritos, orais ou sinalizados vêm sendo construídos de acordo com o passar do tempo, para que facilitem a comunicação dos indivíduos, pois não são estáticos, mas estão em pleno movimento. Assim, adéquam-se às práticas sociais que, por sua vez, adéquam- se aos gêneros. Portanto, os gêneros são produtos das atividades sociais dos humanos, que no desejo de compreenderem uns aos outros, mostram suas formas de pensamento.

Norteadas por essa visão de língua, a partir de 2013, desenvolvemos ações para a formação de docentes de LIBRAS voltadas para o seu ensino por meio dos gêneros textuais.

Vale salientar que em 2012 foi agregado ao grupo mais um docente de LIBRAS, que atuava em uma recém criada escola bilíngue para surdos, no município de Sumé/PB.

Inicialmente, estudamos o documento Orientações Curriculares e Proposição de Expectativas de Aprendizagem para a Educação Infantil e Ensino Fundamental: LIBRAS, da Secretaria Municipal de Educação de São Paulo (2008). Este documento tem como referencial 


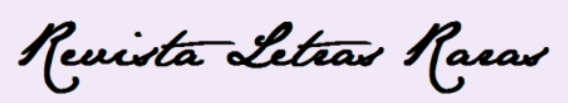

ISSN: 2317-2347 - Vol. 5, Ano 5, № 1 - 2016

teórico a concepção interacionista de linguagem e de ensino de língua a partir dos gêneros textuais, como podemos observar na citação a seguir:

A ênfase no discurso e não em palavras isoladas, e na atribuição de sentido e não na decodificação sem compreensão, caracteriza a concepção de língua como prática social, a qual privilegia a natureza funcional e interativa e não o aspecto formal e estrutural da língua (Marcuschi, 2002).

O discurso se manifesta por meio de diferentes gêneros textuais, eventos linguísticos que se caracterizam muito mais por suas funções comunicativas do que por suas peculiaridades linguísticas e estruturais.

Nessa perspectiva, entendem-se os gêneros textuais como um produto coletivo dos diversos usos da linguagem, e que se realizam de diversos modos, de acordo com as necessidades comunicativas do dia-a-dia da comunidade. Há gêneros eminentemente orais, escritos, informais e formais. (SÃO PAULO/SP, 2008, p. 84)

Com base neste estudo, construímos coletivamente uma proposta curricular para o ensino de LIBRAS nos anos iniciais do Ensino Fundamental. Na verdade, foi feita uma adaptação da proposta da Secretaria de Educação de São Paulo/SP, para a realidade de nossas Escolas.

Dando continuidade a esta iniciativa e com o objetivo de colocar a proposta curricular elaborada em ação, nos anos de 2014 e 2015 procedemos estudos mais aprofundados sobre gêneros textuais e produzimos propostas de ensino de LIBRAS a partir de gêneros estudados, abrangendo todo o Ensino Fundamental. Ao final desse período, quando da avaliação do projeto de extensão desenvolvido em 2015, os docentes de LIBRAS em formação apontaram a necessidade de continuar os estudos na perspectiva dos gêneros textuais e seu ensino, bem como a produzir materiais didáticos adequados para suas práticas pedagógicas (ARAÚJO e outros, 2016)

Com o objetivo de atender a esta demanda, em 2016 vem sendo oferecido um curso de formação de forma ampliada em duas perspectivas. Uma, em relação à abertura de vagas para a formação, englobando docentes de LIBRAS de outros espaços de ensino desta língua. A outra, em relação à colaboração de professores da Unidade Acadêmica de Letras da UFCG, que veem contribuir nos estudos teórico-metodológicos quanto ao ensino de língua como primeira língua (L1) e como segunda língua (L2).

\section{Considerações}




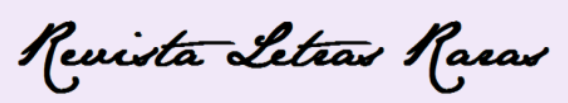

ISSN: 2317-2347 - Vol. 5, Ano 5, № 1 - 2016

Apresentaremos algumas considerações sobre o trabalho de formação docentes discorrido, sob duas óticas. Em primeiro lugar, a partir das falas dos próprios docentes em formação, colhidas quando da avaliação do projeto de extensão de 2015. Em seguida, a partir da nossa visão enquanto professoras formadoras.

Para os docentes em formação, a sistematização mais efetiva dos estudos teóricos e metodológicos sobre gêneros textuais possibilitou a compreensão do próprio gênero e de possibilidades de seu ensino:

Mas o trabalho com os gêneros textuais foi muito melhor. As alunas bolsistas ajudaram muito, as duas, explicando o que é o gênero convite, jogo, também comparando as diferenças e eu consegui entender melhor. (A) ${ }^{3}$

Destacaram, ainda, o caráter fundamental desses encontros de estudos para o fortalecimento do grupo de docentes para o ensino de LIBRAS:

Se parar [a formação], o que vai ser do ensino nas escolas da Paraíba? Vai ensinar o quê? Vai sumir [o ensino de LIBRAS]... É importante que o trabalho continue. Os professores em seus ambientes de trabalho lembram das explicações e isso dá segurança. Se não tiver o planejamento, os professores de LIBRAS se enfraquecem. É importante o grupo estar sempre junto. (A)

Precisamos nos encontrar no próximo ano. Elas [as professoras] estão dizendo que a decisão da continuidade dos estudos é nossa. Mas se não nos encontrarmos para estudar, vamos esquecer tudo e vai ser ruim. Precisamos dar continuidade aos estudos, para nos desenvolvermos e 2016 ser melhor. (J)

Indicaram a necessidade de continuidade do trabalho de formação, com vistas também, a ampliação do currículo de LIBRAS para o Ensino Médio:

Eu quero que continue assim no próximo ano. Que continuemos construindo o currículo do $1^{\circ}$ ao $9^{\circ}$ ano e do $1^{\circ}$ ao $3^{\circ}$ ano do ensino médio. Como? Organizando propostas com mais segurança. Isso é importante. Eu penso que para o próximo ano, o projeto deve focar em cada um desses anos para que tenhamos um material próprio para cada ano (A).

Finalmente, colocaram a necessidade de divulgação do trabalho realizado pelo grupo em relação ao ensino de LIBRAS:

É importante no futuro fazer artigos e apresentá-los $(\mathrm{F})$.

\footnotetext{
${ }^{3}$ Todas as falas apresentadas no item 3 Considerações foram traduzidas livremente para a Língua Portuguesa e constam em Araújo e outros, 2016.
} 


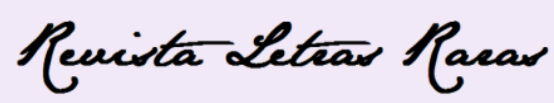

ISSN: 2317-2347 - Vol. 5, Ano 5, № 1 - 2016

Em linhas gerais, ao longo de todo esse período, ao propormos a avaliação dos projetos, os docentes de LIBRAS consideram a relevância das ações de formação quanto a aquisição de conhecimento, a reinvenção da prática de ensino de LIBRAS e, também, de forma muito enfática, a importância do grupo para a constituição deles como professores de LIBRAS.

Sob nossa ótica, além de compartilharmos de suas considerações, apresentamos mais algumas.

Apesar dos vintes anos transcorridos desde que assumimos a perspectiva bilíngue para a educação de surdos, percebemos que a visão estruturalista de língua, advinda do Oralismo, continua, ainda, enraizada nas práticas de ensino de língua nas escolas para surdos, bem como no ensino de LIBRAS como segunda língua em cursos oferecidos aos ouvintes.

Entendemos, também, que o atrelamento local do ensino de LIBRAS à área de Educação e não de Letras tenha, em alguns aspectos, impedido que ações mais arrojadas fossem implementadas, nos estudos, nos materiais didáticos proposto a ser produzidos e na divulgação do trabalho pioneiro por nós realizado.

Apesar destas adversidades locais e de muitas outras advindas das políticas públicas para a educação no Brasil, continuamos acreditando que a formação continuada de docentes constitui-se em um espaço privilegiado para a apropriação do conhecimento, como também para a construção da profissionalidade docente. E como docentes, nos formamos, da mesma forma, em conjunto.

Por fim, temos claro que a formação coletiva e continuada fortalece o enfrentamento das adversidades na busca da conquista por escolas bilíngues públicas de qualidade que venham a atender os anseios da comunidade surda.

\section{Referências}

ALBRES, Neiva de Aquino. e SARUTRA, Moryse Vanessa. Programa curricular de língua brasileira de sinais para surdos. São Paulo: IST, 2012.

ARAÚJO, Larissa Cordeiro; ALVES, Saionara Ferreira; LIMA, Niédja Maria F. de; GIANINI, Eleny; PORTO, Shirley B. das N. Currículo e formação docente: o ensino de LIBRAS em escolas bilíngues para surdos na Paraíba. Relatório final. Programa de Bolsas de Extensão, PROBEX/UFCG, 2016.

BRASIL. Lei Federal n ${ }^{\circ}$ 10.436, de 24 de abril de 2002 (lei da LIBRAS). Brasília: Presidência da República, Casa Civil, Subchefia para Assuntos Jurídicos.

Decreto $n^{\circ} 5626$ de 22 de dezembro de 2005. Brasília: Presidência da República, Casa Civil, Subchefia para Assuntos Jurídicos. 


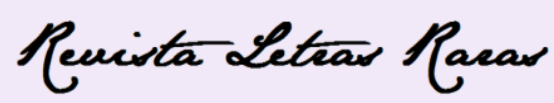

ISSN: 2317-2347 - Vol. 5, Ano 5, № 1 - 2016

FACCI, Marilda Gonçalves Dias. Valorização ou esvaziamento do trabalho do professor. Campinas: Autores Associados, 2004.

FELIPE, Tanya A. Introdução à gramática da LIBRAS. In: BRASIL. Secretaria de Educação Especial. Língua Brasileira de Sinais. Brasília: SEESP, 1997. (Série Atualidades Pedagógicas, v. III).

LIBRAS em contexto: curso básico / livro do professor/instrutor. Brasília: Programa nacional de Apoio à Educação de Surdos, MEC: SEESP/FENEIS, 2001.

FUZA, Ângela Francine, OHUSCHI, Márcia Cristina Greco e MENEGASSI, Renilson José. Concepções de linguagem e o ensino da leitura em língua materna. In: Linguagem \& ensino, Pelotas, v. 14, n.2, p. 479 - 501, jul./ dez.2011.

GIANINI, Eleny. A formação de professores surdos de LIBRAS: a centralidade de ambientes bilíngues em sua formação. Tese (Doutorado em Educação), Programa de Pós-Graduação em Educação, Universidade Federal do Rio Grande do Norte - UFRN, Natal/RN, 2012.

GUIMARÃES, Valter Soares. Formação de professores: saberes, identidade e profissão. Campinas, SP: Papirus, 2004.

LACERDA, Cristina B. F.; MANTELATTO, Sueli A. C. As diferentes concepções de linguagem na prática fonoaudiológica. In: LACERDA, Cristina B. F. de; NAKAMURA, Helenice; LIMA, Maria Cecília (Orgs.). Fonoaudiologia: surdez e abordagem bilíngue. São Paulo: Plexus Editora, 2000. p. 21 - 41.

MOURA, Maria Cecília de. O surdo: caminhos para uma nova identidade. Rio de Janeiro: Editora Revinter, 2000.

SACKS, Oliver. Vendo vozes: uma jornada pelo mundo dos surdos. Tradução: Alfredo Barcellos Pinheiro Lemos Rio de Janeiro: Imago ed., 1990.

SÃO PAULO (SP). Secretaria Municipal de Educação. Diretoria de Declaração Técnica. Orientações Curriculares e proposições de expectativas de aprendizagem para Educação Infantil e Ensino Fundamental: LIBRAS. São Paulo: SME/DOT, 2008.

SKLIAR, Carlos. A localização política da educação bilíngue para surdos. In: SKLIAR, C. (Org.). Atualidade da educação bilíngue para surdos. Porto Alegre: Mediação, 1999. p. 7 - 14.

SLOMSKY, Vilma Geni. Educação bilíngue para surdos: concepções e implicações práticas. Curitiba: Juruá, 2010.

TRAVAGLIA, L. C. Concepções de linguagem. In: proposta de gramática no $1^{\circ}$ e $2^{\circ}$ graus. São Paulo: Cortez, 1996.

Gramática e interação: uma

VÁZQUEZ, Adolfo S. Filosofia da práxis. Buenos Aires: Consejo Latinoamericano de Ciencias Sociales-CLACSO. São Paulo/Brasil: Expressão Popular, 2007.

Recebido em: 29/04/2016

Aceito em: 30/06/2016 